\title{
Effectors Differently Modulating the Dextransucrase Activity of Leuconostoc mesenteroides
}

\author{
Mikihiko Kobayashi, Ikuko Yokoyama and Kazuo Matsuda \\ Department of Agricultural Chemistry, Faculty of Agriculture, \\ Tohoku University, Sendai, Miyagi 980, Japan
}

Received April 24, 1985

\begin{abstract}
Effects of various compounds on the dextransucrase (EC 2.4.1.5) from Leuconostoc mesenteroides was evaluated based on the two catalytic activities of enzyme, that is the hydrolase activity for the substrate, sucrose, and the transferase activity of a D-glucosyl group to an acceptor molecule. The effectors were grouped into six categories by their activation or inhibition of the sucrase and transferase activities of dextransucrase. Type I-A inhibited both activities, type I-B inhibited the sucrase activity, and type I-C inhibited the transferase activity. Type A-A activated both the hydrolase and transferase, and type A-B activated only the transferase. Antagonistic modulation (type IA-A), was shown by methyl $\alpha$-D-glucoside and glycerol, which activated the sucrase and inhibited the transferase. A double reciprocal plot for dextran gave a biphasic pattern which led to $K i$ values for each limb. Based on the biphasic kinetics and the action of antagonistic effectors, the regulation of dextran synthesis was discussed.
\end{abstract}

Dextransucrase (EC 2.4.1.5) catalyzes the transfer of a D-glucosyl group from sucrose to a growing chain of the polysaccharide dextran. ${ }^{1)}$ In our previous paper, ${ }^{2)}$ we demonstrated that the purified dimer of dextransucrase from Leuconostoc mesenteroides NRRL B-1416 was activated by the addition of exogenous dextran $(67 \mu \mathrm{M})$, when the enzyme was assayed for the release of reducing sugar (sucrase activity). However, much greater activation was observed when the amount of dextran synthesized (transferase activity) was assayed. ${ }^{3)}$ A discrepancy between the stimulation of two activities should be explained by more extensive studies. Recently, Luzio and Mayer have reported that dextransucrase catalyzed the hydrolysis of the substrate sucrose ${ }^{4)}$ and that a glucosylated enzyme had three competing activities, hydrolysis, D-glucosyltransfer, and polymerization. 5) In most of the previous papers, the enzyme activity was assayed by measuring either released reducing sugar or synthesized dextran. ${ }^{6)}$ To better understand the reaction mechanism, the dextransucrase reaction should be kinetically evaluated for both sucrase and transferase activities.

In this paper, we describe the effects of various compounds on the dextransucrase activity, which was assayed for both sucrase and transferase activities. Although there have been many reports on various effectors for this enzyme, ${ }^{710)}$ there is no systematic characterization of them. Some kinetic analyses with inhibitors were also conducted to have information on the mechanism of enzyme catalysis.

\section{MATERIALS AND METHODS}

Materials. Dextransucrase from Leuconostoc mesenteroides NRRL B-1416 strain was purified as described previously; ${ }^{3)}$ the enzyme was treated with an endodextranase and the resulting dimeric form was isolated by preparative polyacrylamide gel electrophoresis. A clinical dextran (mol. wt. 75,000 $\pm 25,000$ ) was provided by Meito Sangyo Co., Japan.

Enzyme assays. The standard reaction mixture $(250 \mu \mathrm{l})$ contained a suitably diluted enzyme $(50 \mu \mathrm{l}), 292 \mathrm{~mm}$ sucrose, and $67 \mu \mathrm{M}$ clinical dextran in $40 \mathrm{~mm}$ acetate buffer ( $\mathrm{pH} \mathrm{5.2)}$. After incubation at $30^{\circ} \mathrm{C}$ for $20 \mathrm{~min}$, reactions were stopped by the addition of $\mathrm{NaOH}$ (final $0.2 \mathrm{M}$ ). Enzyme activity was measured with the following procedures. 
Method I. The amount of reducing sugar released from the substrate sucrose was measured by the NelsonSomogyi method as described previously. ${ }^{11)}$ The sucrase activity was measured by this assay method.

Method II. The amount of D-glucose incorporated into the acceptor dextran was measured as follows: To obtain a sufficient amount of dextran for the subsequent purification step, the reaction was conducted for at least $5 \mathrm{hr}$. To the reaction mixture $(250 \mu \mathrm{l})$ was added two volumes of ethanol $(67 \%, \mathrm{v} / \mathrm{v})$, and polysaccharide was recovered by centrifugation at $1,500 \times g$ for $15 \mathrm{~min}$. The precipitate was dissolved in water $(200 \mu 1)$ containing $10 \mathrm{mM} \mathrm{CaCl}_{2}$, and then three volumes of ethanol $(75 \%$, $\mathrm{v} / \mathrm{v}$ ) was added to precipitate the dextran. This precipitation step was repeated thrice. Finally, the precipitate was dissolved in $0.1 \mathrm{M} \mathrm{NaOH}(240 \mu \mathrm{l})$ and neutralized with $0.1 \mathrm{M} \mathrm{HCl}(260 \mu \mathrm{l})$. The total sugar (dextran) was measured by the phenol-sulfuric acid procedure as described previously. ${ }^{12)}$ This assay corresponded to the transferase activity, and most of the results except for the kinetic experiments were obtained by this procedure. An almost quantitative recovery of the dextran was obtained by this method, which was confirmed by using the clinical dextran as a standard.

Method III. For the kinetic analysis, measurement of synthesized dextran was conducted as follows: The reaction mixture $(250 \mu \mathrm{l})$ contained $146 \mathrm{~mm}$ sucrose, clinical dextran (up to $13.4 \mu \mathrm{M}$ concentration), and enzyme solution. The enzyme reaction was ended by heating for $5 \mathrm{~min}$ at $100^{\circ} \mathrm{C}$. The resulting mixture was put on a Sephadex G-50 column $(0.9 \times 4 \mathrm{~cm}$; in a disposable plastic syringe) and eluted with water. The void volume fraction, corresponding to 650 to $1150 \mu$ l of eluate, was collected for the assay of dextran by the phenol-sulfuric acid procedure. The recovery of dextran was quantitative in the range of 0 to $1.0 \mathrm{mg}$ of clinical dextran.

\section{RESULTS}

\section{Effects of metals and chemicals}

Both sucrase and transferase activities were measured in the absence and presence of exogenous dextran (67 $\mu \mathrm{M}$ clinical dextran), and the latter activity was assayed by the method II described above. The ratio of enzyme activity in the absence and presence of dextran was $1.0: 4.4$ for the sucrase activity, and $1.0: 8.0$ for the transferase activity. The sucrase activity was strongly inhibited by SDS (sodium dodecyl sulfate) (Table I). Although $\mathrm{Ca}^{2+}$ slightly activated sucrase activity (Table I), it significantly activated the transferase activity $(475 \sim 519 \%)$. In contrast, transferase activity was strongly inhibited by EDTA, which had almost no effects on the sucrase activity. A mixture of SDS and Triton X-100 is effective in dissociating dextransucrases from Streptococcus mutans. ${ }^{13,14)}$ This mixture activated transferase by $200 \sim 290 \%$, but it caused no sufficient dissociation of Leuconostoc dex-

Table I. Effects of Metals and Chemicals on the DeXtransucrase Activity ${ }^{a}$

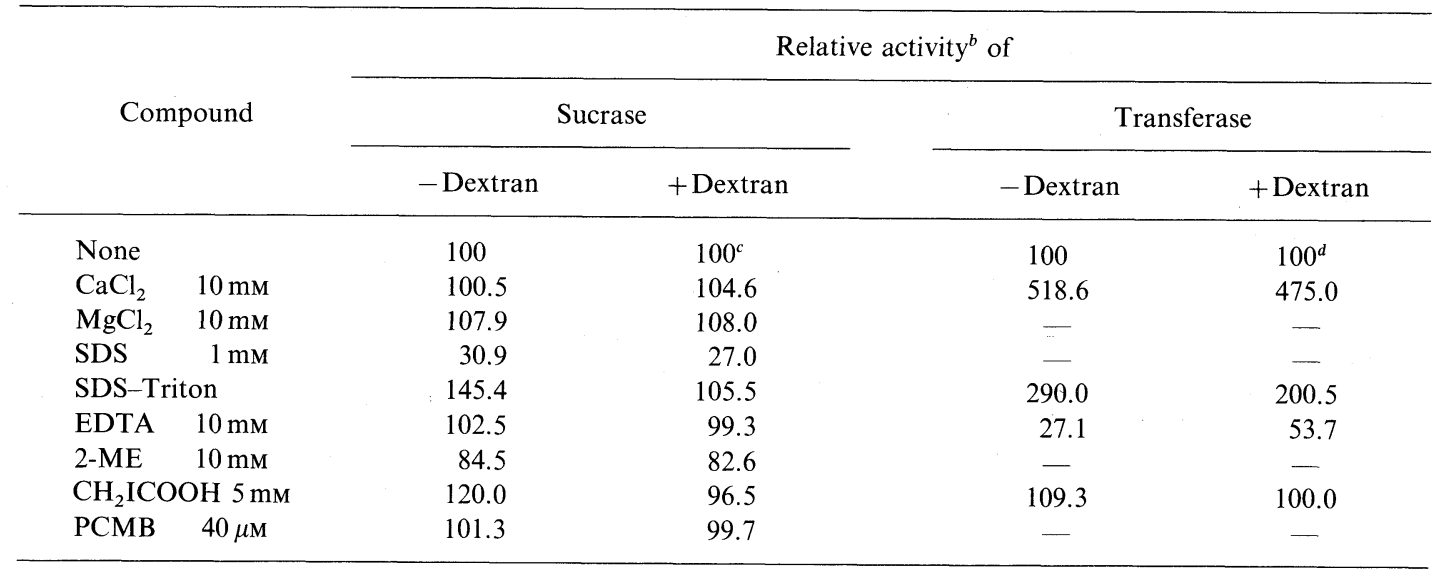

a Abbreviations used: SDS, sodium dodecyl sulfate; SDS-Triton, a mixture of $0.005 \%$ SDS and $0.01 \%$ Triton X100; 2-ME, 2-mercaptoethanol; PCMB, $p$-chloromercuribenzoate.

$b$ In the presence of clinical dextran $(67 \mu \mathrm{M})$.

c The ratio of sucrase activity obtained in the absence and presence of dextran was $100: 440$, and the latter value was taken as 100 in this table.

${ }^{d}$ The ratio of transferase activity obtained in the absence and presence of dextran was $100: 800$, and the latter value was taken as 100 in this table. 
Table II. Effects of Substrate Analogs on the Dextransucrase Activity

\begin{tabular}{|c|c|c|c|c|c|}
\hline \multirow{2}{*}{ Compound } & \multirow{2}{*}{$(\mathrm{mM})$} & \multicolumn{2}{|c|}{ Sucrase } & \multicolumn{2}{|c|}{ Transferase } \\
\hline & & - Dextran & + Dextran & - Dextran & + Dextran \\
\hline None & & 100 & $100^{a}$ & 100 & $100^{b}$ \\
\hline \multirow[t]{2}{*}{ D-Glucose } & 0.1 & 41.9 & 97.2 & - & - \\
\hline & 1 & 20.3 & 89.0 & 105.6 & 93.6 \\
\hline \multirow[t]{2}{*}{ D-Fructose } & 1 & 43.2 & 96.1 & 102.0 & 91.5 \\
\hline & 50 & - & - & 74.3 & 69.1 \\
\hline \multirow[t]{2}{*}{ D-Sorbitol } & 1 & 93.4 & 99.1 & 99.3 & 91.1 \\
\hline & 50 & 95.9 & 116.2 & 104.3 & 87.8 \\
\hline \multirow[t]{2}{*}{ Maltose } & 1 & 91.9 & 118.9 & 87.5 & 111.7 \\
\hline & 50 & - & - & 25.5 & 30.9 \\
\hline \multirow[t]{2}{*}{ Maltitol } & 1 & 87.7 & 102.7 & 90.2 & 100.0 \\
\hline & 50 & 127.9 & 117.6 & 86.3 & 95.6 \\
\hline \multirow[t]{2}{*}{ D-Glucono- $\delta$-lactone } & 1 & 63.5 & 93.4 & 60.9 & 68.1 \\
\hline & 50 & - & - & 36.6 & 56.4 \\
\hline \multirow[t]{4}{*}{ Methyl $\alpha$-D-glucoside } & 0.1 & 66.2 & 100.4 & - & - \\
\hline & 1 & 60.8 & 97.2 & 96.6 & 107.4 \\
\hline & 50 & 154.9 & 114.8 & 69.4 & 84.4 \\
\hline & 100 & 208.2 & 123.5 & 69.2 & 78.9 \\
\hline Glycerol & $10 \%$ & 128.1 & 78.1 & 47.7 & 55.7 \\
\hline
\end{tabular}

a,b See the legend for Table I. $c$ and $d$, respectively.

transucrases (data not showh). Effects of SHreagents on this enzyme were rather similar to those described in our previous paper. ${ }^{8)}$

\section{Effects of low-molecular-weight sugars}

In contrast to the activation of transferase reaction by exogenous dextran (legend for Table I), none of the low-molecular-weight sugars stimulated the transferase activity (Table II). Both D-glucose and D-fructose (1 mM) caused $60 \sim 80 \%$ inhibition of sucrase activity in the absence of acceptor dextran, which was abolished by the addition of dextran. However, the transferase activity was inhibited to only a small extent by these sugars. The transferase activity was significantly inhibited by maltose $(50 \mathrm{~mm})$. Compared with maltitol, sorbitol showed neither activation of sucrase nor inhibition of transferase. Glucono- $\delta$-lactone potently inhibited both activities. For methyl $\alpha$-D-glucoside and glycerol, the sucrase was stimulated by these sugars at higher concentrations, while addition of acceptor dextran suppressed the activation. Both sugars were rather inhibitory on the transferase.

\section{Kinetics with D-fructose and maltose}

Kinetic analysis of D-fructose inhibition was done with varied concentrations of substrate sucrose and dextran. In these experiments, the reaction velocity was expressed as the sucrase activity; the amount of reducing sugar was measured by the method I. Figure 1a shows that $\mathrm{D}$-fructose inhibited the reaction competitively with sucrose and gave a value of $K i$ $44.8 \mathrm{~mm}$. Inhibition of dextransucrase with Dfructose gave a biphasic plot when assayed with various amounts of acceptor dextran (Fig. 1b). In contrast to the competitive inhibition for sucrose, noncompetitive and mixed inhibition were found at higher and lower concentrations of exogenous dextran, respectively. The $K i$ values for two limbs were 283.4 and $107.3 \mathrm{~mm}$, which were more than twice as high as that for sucrose. Similar biphasic kinetics has been observed in measuring the $\mathrm{Km}$ values for dextran as reported previously. ${ }^{2)}$ Inhibition of dextransucrase with maltose showed the same patterns as those with Dfructose, where $K i$ values were much smaller than those with D-fructose (Table III). Moreover, glucono- $\delta$-lactone was a compe- 


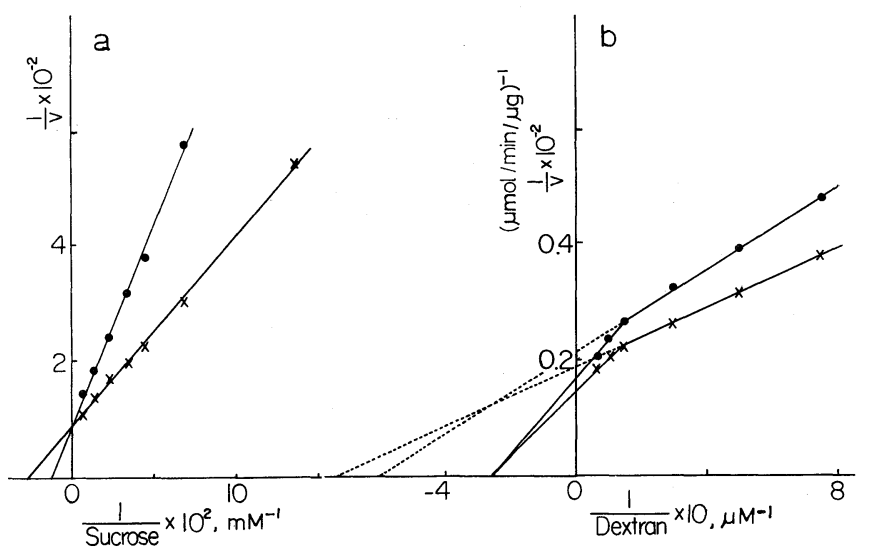

FIG. 1. Inhibition of Dextransucrase with D-Fructose.

(a): Double reciprocal plot with different concentrations of substrate sucrose. (b): Double reciprocal plot with different concentrations of substrate dextran. Initial velocity was assayed in the presence $(\boldsymbol{O})$ and absence $(x)$ of $50 \mathrm{~mm}$ D-fructose. The assay was by method I described in the text.

Table III. Kinetic Constants and Modes of Action of Various Substrate Analogs on the Dextransucrase ACtivity

\begin{tabular}{|c|c|c|c|c|}
\hline \multirow{2}{*}{$\begin{array}{l}\text { Substrate } \\
\text { analog }\end{array}$} & \multicolumn{4}{|c|}{$K i(\mathrm{~mm})$ for Substrate } \\
\hline & Sucrose & $(\text { Type })^{a}$ & $\operatorname{Dextran}^{b}$ & $(\text { Type })^{a}$ \\
\hline D-Fructose & 44.8 & $\mathrm{C}$ & $\begin{array}{l}107.3 \\
283.4\end{array}$ & $\begin{array}{l}\mathrm{M} \\
\mathrm{NC}\end{array}$ \\
\hline Maltose & 5.4 & $\mathrm{C}$ & $\begin{array}{r}72.0 \\
126.3\end{array}$ & $\begin{array}{l}\mathrm{M} \\
\mathrm{NC}\end{array}$ \\
\hline $\begin{array}{l}\text { D-Glucono- } \delta \text {-lactone } \\
\text { Methyl } \alpha \text {-D-glucoside }\end{array}$ & $\begin{array}{r}7.7 \\
82.4\end{array}$ & $\begin{array}{l}\mathrm{C} \\
\mathrm{C}\end{array}$ & $\begin{array}{c}- \\
217.4 \\
450.5\end{array}$ & $\begin{array}{l}- \\
\mathrm{M} \\
\mathrm{NC}\end{array}$ \\
\hline \multirow{2}{*}{$\begin{array}{l}\text { Substrate } \\
\text { analog }\end{array}$} & \multicolumn{4}{|c|}{$K a(\mathrm{~mm})$ for Substrate } \\
\hline & Sucrose & $(\text { Type })^{a}$ & $\operatorname{Dextran}^{b}$ & $(\text { Type })^{a}$ \\
\hline Methyl $\alpha$-D-glucoside & 45.4 & $\mathrm{M}$ & $\begin{array}{r}60.8 \\
187.0\end{array}$ & $\begin{array}{l}\mathrm{M} \\
\mathrm{NC}\end{array}$ \\
\hline
\end{tabular}

a C, competitive; $\mathrm{M}$, mixed type; $\mathrm{NC}$, noncompetitive.

$b$ Double reciprocal plots showed a biphasic pattern.

titive inhibitor of the sucrase activity.

\section{Kinetics with methyl $\alpha$-D-glucoside}

As shown in Table II, methyl $\alpha$-D-glucoside stimulated the sucrase and inhibited the transferase. Thus, the reaction velocity was measured by respective sucrase and transferase activities. The latter activity was obtained by measuring the amount of dextran synthesized (method III). For sucrase, methyl $\alpha$-D-gluco- side activated the enzyme in a mixed-type manner giving a $K a$ value of $45.4 \mathrm{~mm}$ for sucrose (Fig. 2a). Although the activation of sucrase was also found for substrate dextran, the biphasic pattern was again observed (Fig. $2 b$ ). The $K a$ values of $187.0 \mathrm{~mm}$ (noncompetitive-type) and $60.8 \mathrm{~mm}$ (mixed-type) corresponded to the higher and lower concentrations of dextran, respectively (Table III). For the transferase, a competitive inhibition 

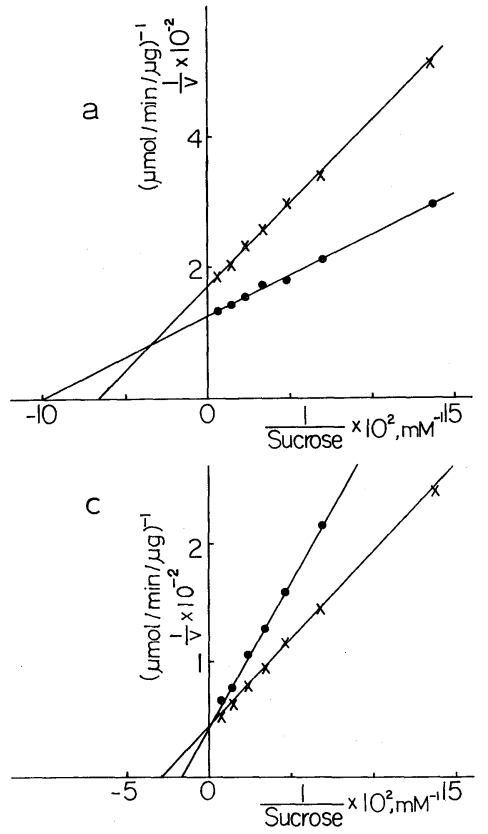
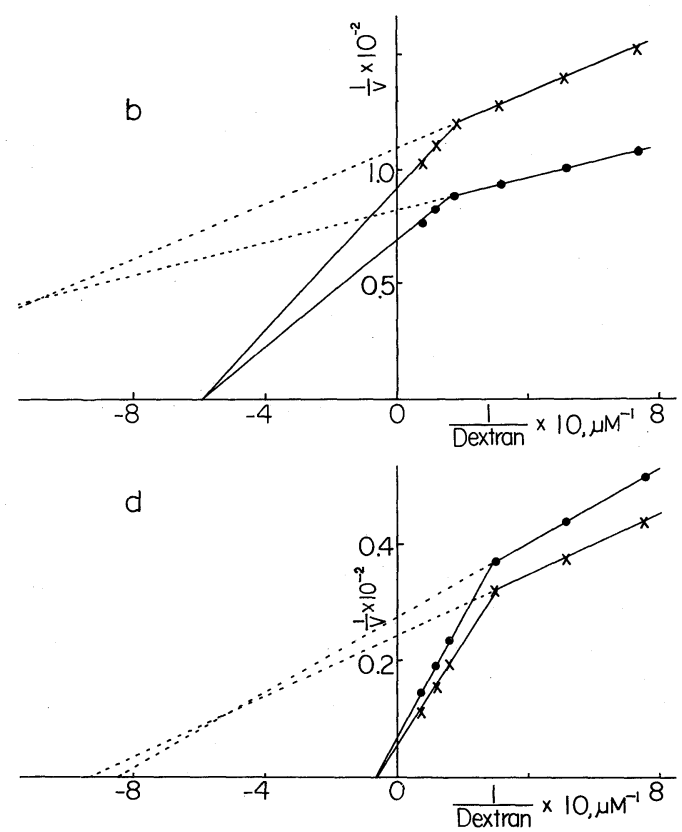

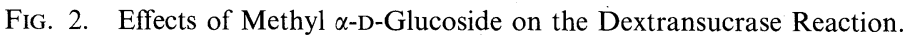

(a) and (c): Double reciprocal plots with different concentrations of sucrose. (b) and (d): Double reciprocal plots with different concentrations of dextran. Initial velocity was assayed in the presence $(\boldsymbol{O})$ and absence $(\times)$ of $50 \mathrm{~mm}$ methyl $\alpha$-D-glucoside. The assay was by method I for (a) and (b), and method III for (c) and (d).

of enzyme for sucrose was found with a $K i$ value of $82.4 \mathrm{~mm}$ (Fig. 2c). The biphasic inhibition of transferase also gave two inhibition constants for dextran (Fig. 2d). At higher concentrations of dextran, the inhibition was noncompetitive, while mixed inhibition was observed at lower concentrations of dextran.

\section{DISCUSSION}

The results shown in Tables I and II indicated that the effectors might be classified into six categories according to the combination of inhibition, activation and lack of effects on the sucrase and transferase activities. Among the inhibitors, glucono- $\delta$-lactone inhibited both sucrase and transferase (type IA), while D-fructose and EDTA inhibited mainly sucrase (type I-B) and transferase (type I-
C), respectively. As with the Streptococcus dextransucrase, ${ }^{13)}$ SDS-Triton $\mathrm{X}-100$ activated both activities (type A-A), whereas $\mathrm{Ca}^{2+}$ gave strong activation of glucosyltransfer reaction (type A-B). Methyl $\alpha$-D-glucoside and glycerol showed activation on sucrase and inhibition on transferase (type IA-A). Therefore, each effector has different actions on the dextransucrase reaction, i.e., there are various types of effectors, which specifically modulate the sucrase activity or transferase activity or both. These results clearly support the idea that the dextransucrase reaction should be separated into sucrase and transferase steps with respect to the action of effectors. The ping-pong $\mathrm{Bi}-\mathrm{Bi}$ mechanism, shown in reaction $\mathbf{1}$, proposed for the dextransucrase, ${ }^{15)}$ is not in conflict with the above definition, where the sucrase

\begin{tabular}{|c|c|c|c|}
\hline$\underset{\downarrow}{\operatorname{Sucrose}(\mathrm{A})}$ & D-Fructose(P) & $\mathrm{D}_{\downarrow}-\mathrm{Glucose}_{n}(\mathrm{~B})$ & D-Glucose ${ }_{\uparrow+1}(\mathrm{Q})$ \\
\hline
\end{tabular}




$$
\begin{aligned}
& \text { Sucrose }+ \text { Enzyme } \rightarrow \text { D-Fructose }+ \text { D-Glucosyl }- \text { Enzyme } \\
& \text { D-Glucosyl }- \text { Enzyme }+ \text { D-Glucose }_{n} \rightarrow \text { D-Glucose } \text { El }_{n}+\text { Enzyme }^{- \text {En }}
\end{aligned}
$$

activity catalyzes reaction $\mathbf{2}$. Then, the intermediate D-glucosylated enzyme, which could be recently prepared and characterized by Mayer's group, ${ }^{4)}$ reacts with dextran to transfer D-glucosyl residue to the acceptor dextran molecule as shown in reaction 3 .

In 1958, Stringer and Tsuchiya reported extensive kinetic studies on the effect of methyl $\alpha$-D-glucoside on the dextransucrase reaction. ${ }^{16)}$ They found that methyl $\alpha$-D-glucoside increased the $V_{\max }$ value while decreased the yield of high-molecular-weight dextran. More recently, several authors confirmed the dual role of this effector on the dextransucrase reaction and gave various explanations of the reaction mechanism, mainly based on the efficiency of methyl $\alpha$-D-glucoside as an acceptor molecule. ${ }^{17 \sim 21)}$ However, none of the papers describe the evaluation of this effector for the respective sucrase and transferase activities, which could be distinguishable by the kinetic approach. Our studies on the kinetics of methyl $\alpha$-D-glucoside indicated that the transferase activity of dextransucrase was rather inhibited ( $K i$ of $82.4 \mathrm{~mm}$ for sucrose), though the sucrase activity was stimulated ( $K a$ of $45.4 \mathrm{~mm}$ for sucrose). Among the sucrose analogs tested, D-fructose, maltose, and methyl $\alpha$ D-glucoside inhibited the transferase, where the double reciprocal plots for varied concentrations of dextran gave sharp downward biphasic patterns (Fig. $1 \mathrm{~b}$ and $2 \mathrm{~b}$, d). The biphasic plots led to $K m$ (or $K i$ ) values for each limb and the type of inhibition by these analogs was competitive for sucrose, but mixed and noncompetitive for dextran (Table III). These results suggest that dextransucrase has an allosteric property in the synthesis of dextran molecules. In this respect, it is interesting to note that dextransucrases from six strains of $L$. mesenteroides had multiple forms of activity, ${ }^{22)}$ and that enzymes from NRRL B$1299,{ }^{7,8,11)} \mathrm{B}-512 \mathrm{~F},{ }^{12)}$ and B-1416 ${ }^{3)}$ were composed of oligomer forms. Since aggregated oligomer forms of the enzyme showed higher efficiency of glucan synthesizing (transferase) activity, ${ }^{23)}$ the transferase activity might be regulated allosterically by the inter-conversion of oligomer forms.

\section{REFERENCES}

1) E. J. Hehre, Science, 93, 237 (1941).

2) M. Kobayashi, I. Yokoyama and K. Matsuda, Agric. Biol. Chem., 48, 221 (1984).

3) I. Yokoyama, M. Kobayashi and K. Matsuda, Agric. Biol. Chem., 49, 1385 (1985).

4) G. A. Luzio and R. M. Mayer, Carbohydr. Res., 111, 311 (1983).

5) G. A. Luzio, V. K. Parnaik and R. M. Mayer, Carbohydr. Res., 121, 269 (1983).

6) R. L. Sidebotham, Advan. Carbohydr. Chem. Biochem., 30, 371 (1974).

7) M. Kobayashi and K. Matsuda, Biochim. Biophys. Acta, 397, 69 (1975).

8) M. Kobayashi and K. Matsuda, J. Biochem., 79, 1301 (1976).

9) T. J. Grier and R. M. Mayer, Arch. Biochem. Biophys., 212, 651 (1981).

10) K. Ono, D. W. Nuessle and E. E. Smith, Carbohydr. Res., 88, 119 (1981).

11) M. Kobayashi and K. Matsuda, Biochim. Biophys. Acta, 370, 441 (1974).

12) M. Kobayashi and K. Matsuda, Biochim. Biophys. Acta, 614, 46 (1980).

13) G. A. Luzio, D. A. Grahame and R. M. Mayer, Arch. Biochem. Biophys., 216, 751 (1982).

14) V. K. Parnaik, G. A. Luzio, D. A. Grahame, S. L. Ditson and R. M. Mayer, Carbohydr. Res., 121, 257 (1983).

15) M. Kobayashi and K. Matsuda, Carbohydr. Res., 66, 277 (1978).

16) C. S. Stringer and H. M. Tsuchiya, J. Am. Chem. Soc., 80, 6620 (1958).

17) F. A. Bovey, J. Poly. Sci., 35, 191 (1959).

18) M. M. McCabe and E. E. Smith, Carbohydr. Res., 63, 223 (1978).

19) R. M. Mayer, M. M. Mathews, C. L. Futerman, V. K. Parnaik and S. M. Jung, Arch. Biochem. Biophys., 208, 278 (1981).

20) G. L. Cote and J. F. Robyt, Carbohydr. Res., 111, 127 (1982).

21) J. F. Robyt and S. H. Eklund, Carbohydr. Res., 121, 279 (1983). 
22) I. Yokoyama, M. Kobayashi and K. Matsuda, Agric. Biol. Chem., 49, 501 (1985).
23) M. Kobayashi and K. Matsuda, Agric. Biol. Chem., 41, 1931 (1977). 